\title{
The Impact of Maintenance Factors on Sustainability of Green Buildings in Nairobi County, Kenya.
}

\author{
Derrick Asuzah, Stephen Diang’a, Bernard Mugwima
}

\begin{abstract}
Green buildings are relatively new in the construction industry, especially in Kenya and serious questions regarding their maintenance beg answers as little has been documented. This study therefore, sought to assess the impact of maintenance factors on sustainability of green buildings in Nairobi County. A survey to investigate; maintenance problems, maintenance policies, maintenance strategies and maintenance management tools/techniques in relation to sustainability of green buildings was delimited to a sample size of 25 LEED certified buildings in Nairobi County and 86 registered green building practitioners. The survey achieved 53\% response rate and data analysis was carried out using a quantitative approach. The findings indicate that, the maintenance strategy variable seemed not to have a significant relationship with the outcome variable, hence it was dropped from the model. The final logistic regression model shows that, the odds for sustainability of green buildings are 1.44, 3.72 and 2.89 times higher when there is proper management of maintenance problems, adequate maintenance policies and proper maintenance management tools/techniques respectively, holding all other factors constant. The results highlighted the need of a paradigm shift in maintenance management of green buildings hence, the proposed framework in figure 2 that will enable maintenance personnel to execute their work in an efficient manner. From an academic perspective, the findings contribute to the pool of knowledge available in the area of green buildings maintenance.
\end{abstract}

Keywords: Green Buildings, Sustainability, Maintenance.

\section{INTRODUCTION}

Like other infrastructures, green buildings need maintenance to keep their designed performance and to meet the upgraded different functional requirements (Doos et al., 2016). Bombugala and Atputharajah (2010) recognizes green buildings as structures created using processes that are environmentally responsible and resources-efficient through

Revised Manuscript Received on July 02, 2020

* Correspondence Author

Derrick Asuzah, Student, Masters in Construction Project Management, Jomo Kenyatta University of Agriculture and Technology (JKUAT), Nairobi, Kenya

Prof. Stephen Diang'a, Department of Construction Management, School of Architecture and Building Sciences (SABS), Jomo Kenyatta University of Agriculture and Technology (JKUAT), Nairobi, Kenya.

Dr. Bernard Mugwima, Centre for Urban Studies, Jomo Kenyatta University of Agriculture and Technology (JKUAT), Nairobi, Kenya.

(C) The Authors. Published by Blue Eyes Intelligence Engineering and Sciences Publication (BEIESP). This is an open access article under the CC BY-NC-ND license (http://creativecommons.org/licenses/by-nc-nd/4.0/) the building life cycle. Fawaz (2013) defines maintenance as a set of organized activities, technical and administrative, that are carried out in order to retain an item in, or restore it to a state in which it can perform a required function. Green buildings are relatively new in the Kenyan construction industry and their performance in terms of maintenance management have not been adequately documented. Despite a few buildings such as the Dunhill Towers in Westlands boasting with the green status, Fawaz (2013) echoes that, most of the green property management companies still use the traditional maintenance management practices. This is a clear indication of a fragmented maintenance process that leads to inefficiency of mechanical systems, customer complaints due to dissatisfaction with their facility or space environmental conditions and eventually higher utility bills and maintenance costs. Experiences around the world lead us to believe that, maintenance policies are a sure way of maintaining resource-efficient infrastructure that will reap benefits over the whole operational phase of buildings (Mohanty, 2012). The policies provide a management framework to the maintenance personnel to determine appropriate maintenance strategy and managerial tools/techniques (Lee \& Scott, 2009). There are usually several strategic options available in maintenance works; corrective, preventive and condition-based maintenance. As companies move toward regular maintenance, it is becoming increasingly important that they make available managerial tools and methodologies to gauge and to help not only maintain but improve their green performance (Fawaz, 2013). To support more planned maintenance approaches (preventive, predictive), innovative approaches such as Building Information Modelling (BIM) have been visualized by Bortolini et al. (2016) as a solution to most of the managerial problems witnessed during maintenance of green buildings. Azahar and Mydin (2014) recommends use of a computerized maintenance management system (CMMS) in order to automate most of the logistical functions performed by maintenance staff and management. Efficient maintenance management of green buildings is coupled with several advantages. Bombugala and Atputharajah (2010) acknowledge that, sound maintenance of the green building concept results into reduction of carbon emissions by $35 \%$, water usage by $40 \%$, the solid waste by $70 \%$ and energy usage by $50 \%$. Therefore, a paradigm shift is needed to address the fragmented maintenance process of green buildings as highlighted by Fawaz (2013).

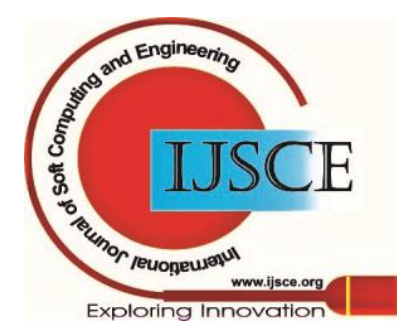


To fill the existing gap, this study sought to develop a framework which will undoubtedly bring consistency in planning, implementation and monitoring of green buildings maintenance.

\section{OBJECTIVES OF THE STUDY}

$\checkmark$ To examine the extent to which maintenance problems affects sustainability of green buildings.

$\checkmark$ To establish the extent to which maintenance policies, strategies and management tools/techniques affects sustainability of green buildings.

Source: Author, 2020

$\checkmark$ To formulate a framework to guide the quality of maintenance works in green buildings.

\section{RESEARCH METHODOLOGY}

The study utilized a survey research design and the sample size was made up of 25 LEED certified buildings in Nairobi County and 86 registered green building practitioners. Two sampling techniques were employed: first, a census for LEED certified buildings and secondly, simple random sampling technique for registered green building practitioners. Questionnaires were the only instruments for data collection and the survey achieved 53\% response rate from the facility managers and the registered green building practitioners. Data analysis (descriptive and inferential statistics) was executed using $\mathrm{R}$ software version 3.4 .3 and the results presented in form of tables, bar charts and mathematical equations.

\section{RESEARCH FINDINGS}

\section{A. Demographic Characteristics of the Respondents}

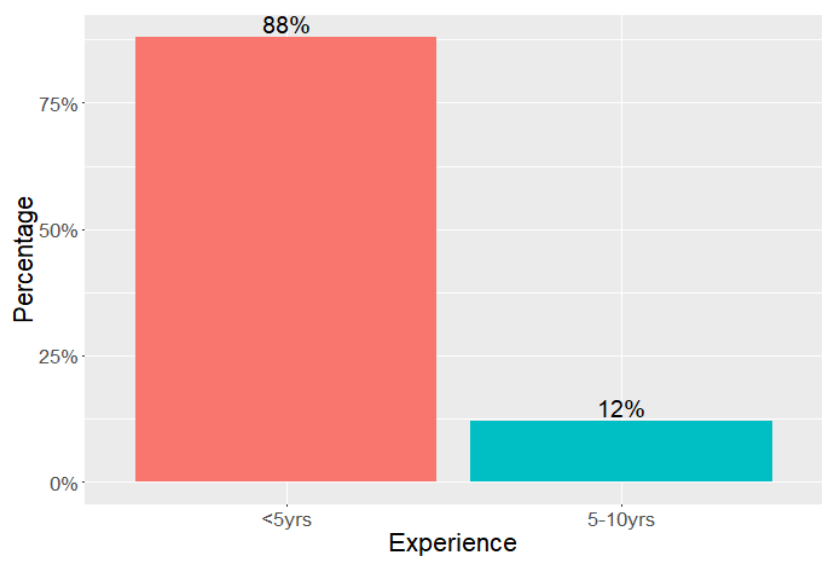

Fig. 1: Respondents Work Experience

Source: Field survey, 2020

Fig.1 depicts that, $88 \%$ of the respondents have work experience of less than five years while $12 \%$ of the respondents have worked for a period ranging from five to ten years. The high frequency of respondents working less than five years supports the belief that, green buildings are relatively new in the Kenyan construction industry.

\section{B. Correlation Analysis}

Table1: Spearman's Rank Correlations for the Variables

\begin{tabular}{|c|c|c|c|c|c|}
\hline & ustainability & Problems & Policies & Strategies & Tools \\
\hline Sustainability & 1 & -0.2045225 & -0.02219276 & -0.0612082 & 0.2527113 \\
\hline Problems & -0.20452254 & 1 & -0.0886317 & 0.2541043 & -0.1872761 \\
\hline Policies & -0.02219276 & -0.0886317 & 1 & 0.2754239 & 0.2754239 \\
\hline Strategies & -0.06120823 & 0.2541043 & -0.27123 & 1 & -0.5106659 \\
\hline Tools & 0.25271128 & -0.187 & 0.27542393 & -0.5106659 & 1 \\
\hline \multicolumn{3}{|c|}{$\begin{array}{l}\text { A positive relationship between maintenance management } \\
\text { tools/techniques and sustainability of green buildings } \\
\text { indicates that, a value increase in the predictor variable causes } \\
\text { a value increase in the dependent variable. Whereas, a } \\
\text { negative relationship between the three variables } \\
\text { (maintenance problems, maintenance policies, maintenance } \\
\text { strategies) and sustainability of green buildings indicates that, } \\
\text { a value increase in the predictor variable causes a value } \\
\text { decrease in the dependent variable and vice versa. }\end{array}$} & \multicolumn{3}{|c|}{$\begin{array}{l}\text { Tools = Maintenance Management Tools/Techniques } \\
\text { Strategies = Maintenance Strategies } \\
\text { Model } 1 \text { did not provide an overall good fit for the data with } \\
\text { a Hosmer Lemeshow goodness of fit test of } \chi 2 \text { at d.f }=3 \text {, } \\
9.2078 \text {, p-value }=0.0267(p<.05 \text { ) which implies that at } \alpha= \\
0.05 \text { the model does not fit the data. Furthermore, the above } \\
\text { model did not yield to a significant coefficient for } \\
\text { maintenance strategies. To remedy this a better model was } \\
\text { developed by dropping the maintenance strategy variable } \\
\text { which seemed not to have a significant relationship with the } \\
\text { outcome variable in the model and the following logistic } \\
\text { regression equation model (Model } 2 \text { ) was developed. }\end{array}$} \\
\hline
\end{tabular}
is as shown below.

\section{Sustainability $=\beta$ problems $+\beta$ policies $+\beta$ tools +}

$\beta$ strategies $+\beta_{0}+\underline{\varepsilon}_{i}$

Whereby;

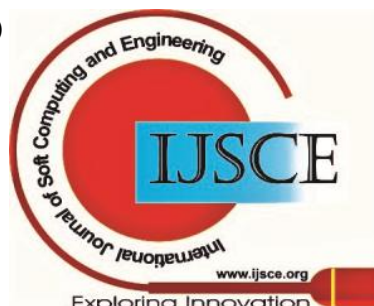


Sustainability $=\boldsymbol{\beta}$ problems $+\boldsymbol{\beta p o l i c i e s}+\boldsymbol{\beta}$ tools $+\boldsymbol{\beta}_{\mathbf{0}}+\underline{\varepsilon}_{\mathrm{i}}$ Model 2 fits the data well at $\alpha=0.05$ with a Hosmer Lemeshow goodness of fit test of $\chi 2$ at d.f $=2,5.9879$, $p$-value $=0.05009(\mathrm{p}>.05)$. Table (2. 21i)ovides a summary of both models.

Table 2: Logistic Regression Models

\begin{tabular}{|c|c|c|c|c|c|c|c|c|}
\hline \multirow[b]{2}{*}{ Variables } & \multicolumn{4}{|c|}{ Model 1} & \multicolumn{4}{|c|}{ Model 2} \\
\hline & $\beta$ & & SE & OR & $\beta$ & & SE & OR \\
\hline Constant & -5.3432 & $* * *$ & 0.2783 & 0.01 & -5.2569 & $* * *$ & 0.2654 & 0.01 \\
\hline Problems & 0.3587 & $* * *$ & 0.0098 & 1.43 & 0.3639 & $* * *$ & 0.0093 & 1.44 \\
\hline Policies & 1.2905 & $* * *$ & 0.0507 & 3.64 & 1.3128 & $* * *$ & 0.0481 & 3.72 \\
\hline Tools & 0.6273 & $*$ & 0.2572 & 3.05 & 0.5976 & $*$ & 0.2449 & 2.89 \\
\hline Strategies & 0.1841 & & 0.2677 & 1.2 & & & & \\
\hline$-2 L L$ & 1294.2 & & & & 1397.7 & & & \\
\hline$\chi^{2}$ & $\begin{array}{c}\text { 2588.4, df } \\
=4 \\
\mathrm{p}<.001\end{array}$ & & & & $\begin{array}{c}\text { 2795.4, df } \\
=3 \\
\mathrm{p}<.001\end{array}$ & & & \\
\hline $\begin{array}{c}\text { Nagelkerke } \\
\mathrm{R}^{2}\end{array}$ & $28.01 \%$ & & & & $27.82 \%$ & & & \\
\hline
\end{tabular}

Notes:

$*=p<.05 ; * * *=p<.001$.

\section{SE Standard Error}

\section{OR Odds Ratio}

Source: Author, 2020

\section{Regression Output Interpretation}

The overall significance of the logistic model given by the Likelihood Ratio Test (LRT) is $\chi 2$ at d.f $=3$, 2795.4, p-value $=2.2 \mathrm{e}^{\wedge}-16(\mathrm{p}<.001)$ implies that at $\alpha=0.05$ the maintenance factors contribute significantly to the prediction of the sustainability of green buildings. We can therefore conclude that there is a statistical significance for factors under equation analysis. This can be further confirmed using Wald tests that are used to evaluate the significance of a single coefficient in the model. The Wald tests for each of the coefficients in the model are illustrated in table 3.

The logistic regression coefficients gave the amount of log odds increase/decrease in sustainability of green buildings when maintenance factors of green buildings are taken into consideration. The log odds for the maintenance factors were converted to odds ratios for easy interpretation. The following is a detailed explanation of the odds ratios from table 2 .

\section{$>$ Maintenance Problems}

Odds of realizing the benefits of green buildings is 1.44 times lower when maintenance problems are poorly handled compared to the proper management of maintenance problems controlling for all other factors.

Table 3: The Wald Tests

\begin{tabular}{|c|c|c|c|c|c|c|}
\hline Coefficients & $\chi^{2}$ & d.f & Wald & & \multicolumn{2}{|c|}{ 95\% confidence interva } \\
\hline Constant & 392.4 & 1 & -19.8 & $* * *$ & -5.7891 & -4.7461 \\
\hline $\begin{array}{c}\text { Maintenance } \\
\text { Problems }\end{array}$ & 746.4 & 1 & 27.3 & $* * *$ & 1.2189 & 1.4073 \\
\hline $\begin{array}{c}\text { Maintenance } \\
\text { Policies }\end{array}$ & 1504.5 & 1 & 38.8 & $* * *$ & 0.3457 & 0.3825 \\
\hline $\begin{array}{c}\text { Maintenance } \\
\text { Tools }\end{array}$ & 6 & 1 & 2.44 & $*$ & 0.1271 & 1.0904 \\
\hline
\end{tabular}

Notes: $*=p<.05 ; * * *=p<.001$.

d.f Degree of Freedom

Source: Author, 2020

\section{$>$ Maintenance Policies}

Odds of realizing the benefits of green buildings is 3.72 times higher when adequate maintenance policies are adopted compared to adoption of poor maintenance policies controlling for all other factors.
Odds of realizing the benefits of green buildings is 2.89 times higher when proper maintenance tools/techniques are adopted compared to the adoption of improper

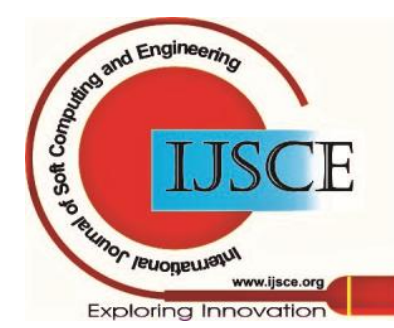


maintenance management tools/techniques controlling for all other factors.

\section{$>$ Intercept}

The intercept (constant) represents the logit of probability of realizing the benefits of green buildings if all the maintenance factors are absent.

Therefore, the coefficient for the intercept represents a decrease in the log odds by -5.2569 in realizing the benefits of green buildings, given that all the maintenance factors are absent.

\section{PROPOSED FRAMEWORK.}

The data analysis results informed this study's framework that will enable facility managers and green building practitioners to achieve consistency in planning, implementation and monitoring of green buildings maintenance. This section therefore highlights the components of the proposed maintenance management framework (Fig.2). Ultimately, the facility maintenance management tools named in the framework requires internet (Wi-Fi) to be able to function as intended.

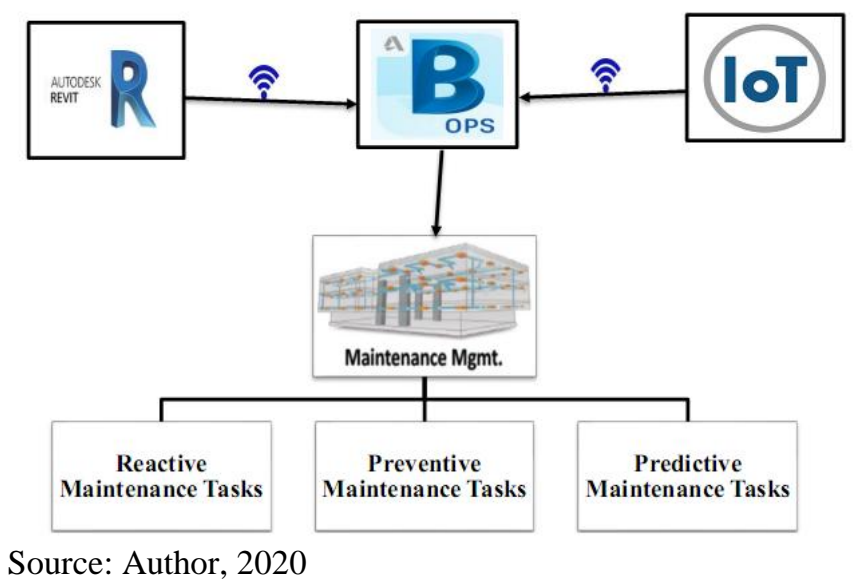

Fig. 2: Maintenance Management Framework

\section{a) Autodesk Revit As-Built Model}

It is acknowledged that, the more accurate and real-time information is available for facility managers, the greater the opportunity for the enhancement of processes throughout the operation and maintenance phase (Matarneh et al., 2018). An as-built Revit model has a critical role to perform as a contributor to a well-designed facilities management (FM) system; by supplying data about all of the spatial and graphical elements, including data that can be used to populate the COBie worksheets (Kensek, 2015). Construction Operations Building Information Exchange (COBie) worksheets improves the facility handover process by providing a non-geometric structured data available for the facility management team use.

\section{b) IoT Beacons \& Smart Sensors}

Internet of Things (IoT) can be defined as the network of physical devices and objects embedded with electronics, software, sensors and network connectivity which enable these objects to collect and exchange data (Institute of Workplace and Facilities Management, 2018). Today's smart buildings are utilizing beacons and smart sensors to increase maintenance efficiency. There are two major types of Internet of Things (IoT) sensors in facility management. The first is temperature and humidity control sensors. These devices track environmental changes to keep occupants comfortable without giving them total control of a room's thermostat (McGaw \& Miller, 2019). The second type of sensor is machine listening and vibration detection sensors. These sensors are placed on larger mechanical assets and alert facility managers of equipment failures or performance changes. A good example of sensors that can be integrated with BIM 360 Ops is the panoramic power sensors. Beacons are the nodes of the Internet of Things (IoT). In a workplace with dozens of deployed sensors, beacons tie them all together and relay the continuous data they're transmitting (Livnat, 2020). In other words, beacons are meant to bring order to the IoT.

\section{c) Autodesk BIM 360 Ops}

BIM 360 Ops is a web-based service that lets maintenance personnel to jumpstart asset maintenance by adding assets from Revit, BIM 360 Field, Internet of Things (IoT) solutions and even spreadsheets. Prior to exporting locations and/or assets it is important to install the BIM 360 Ops Exporter. Assets that can be viewed include: documents and models, maintenance checklists, scheduling and maintenance history. It also includes support for (Work Orders) ticket creation (by smart devices; phone or tablet where for instance maintenance personnel can access and update asset information while in the field without need for paper tickets or hard copy manuals) and management for reactive, preventative and predictive maintenance. BIM 360 Ops allows real time maintenance alerts for work teams and sends the right data to the right personnel at the right time. Information is conveyed through a tidy Graphical User Interface (GUI) that seems focused on usability, displaying only relevant and useful data to the end-users while hiding all the backend stuff for the more advanced user (or admin).

\section{CONCLUSIONS AND FUTURE RESEARCH}

The findings indicate that, three maintenance factors (maintenance problems, maintenance policies and maintenance tools/techniques) contribute significantly to the prediction of the sustainability of green buildings. Maintenance policies emerged as the top most factor among those under equation analysis. This is in line with the findings of Mohanty (2012) who echoes that, maintenance policies are a sure way of maintaining resource-efficient infrastructure that will reap benefits over the whole operational phase of buildings. Finally, the results highlighted the need for a paradigm shift in maintenance management of green buildings hence, the proposed framework that will help maintenance personnel to execute their work in an efficient manner. From an academic perspective, the findings contribute to the pool of knowledge available in the area of green buildings maintenance.

The study recommends further research in the following two areas that could not be studied appropriately in the course of this work;

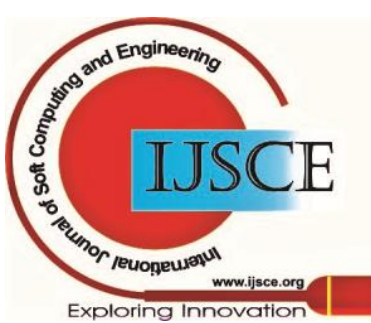


$\checkmark \quad$ Since this study addressed the subject of maintenance management in green buildings, it would be interesting to study the same subject in conventional buildings and compare the results.

$\checkmark \quad$ Future studies are required to look into the aspect of green buildings from a whole project life cycle perspective as this study only concentrated on the operation and maintenance phase.

\section{REFERENCES}

1. Azahar and Mydin. (2014). Potential of computerized maintenance management system in facilities management. Penang, Malaysia: Universiti Sains Malaysia.

2. Bombugala and Atputharajah . (2010). Sustainable development through green building concept in Srilanka. International conference on sustainable built environment (p. 6). Kandy: Central engineering consultancy bureau.

3. Bortolini et al. . (2016). BIM for the integration of Building Maintenance Management: A case study of a university campus . 11th European Conference on Product \& Process Modelling (p. 8). Limassol, Cyprus: ResearchGate.

4. Doos et al. (2016). Assessing the sustainable building maintenance management need for iraqi governmental buildings. Applied Research Journal, Vol.2, Issue, 3, Pp. 88-96.

5. Fawaz, B. (2013). Maintenance management of green buildings in Nairobi County. Nairobi: University of Nairobi.

6. Institute of Workplace and Facilities Management. (2018). Internet of Things for Facilities Management. Retrieved from IWFM Web Site: https://www.iwfm.org.uk/

7. Kensek, K. (2015). BIM Guidelines Inform Facilities Management Databases: A Case Study over Time . Buildings, Pp. 899-916.

8. Lee \& Scott. (2009). Overview of maintenance strategy, acceptable maintenance standard and resources from a building maintenance operation perspective. Journal of Building Appraisal, Pp. 269 - 278.

9. Livnat, N. (2020). Office IoT: A Gateway to Smart Facility Management. Retrieved from SpaceIQ Web Site: https://spaceiq.com/

10. Matarneh et al. (2018). Developing an Interoperability Framework for Building Information Models and Facilities Management Systems . Proceedings of the Creative Construction Conference (p. 10). Ljubljana, Slovenia: Diamond Congress Ltd.

11. McGaw \& Miller. (2019). BIM 360 Ops for Data Centers: An Application Review. Retrieved from Autodesk University Web Site: https://www.autodesk.com/autodesk-university/

12. Mohanty, B. (2012). Low Carbon Green Growth Roadmap for Asia and the Pacific. United Nations publication.

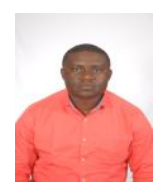

\section{AUTHOR'S PROFILE}

Capt. (Arch.). Derrick Asuzah, Student, Masters in Construction Project Management, Jomo Kenyatta University of Agriculture and Technology (JKUAT), Nairobi, Kenya

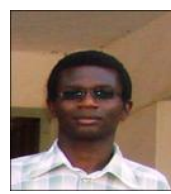

Prof. Stephen Diang'a

A. Academic Professional Qualification

B. Architecture (U.O.N), M. Arch (U.O.N), PhD

(Kwazul Natal), RSA

B. Specialization

Construction Project Management, Construction Contract, Documentation, Project Risk Management, Architecture

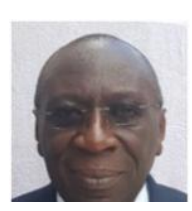

\section{Dr. Bernard Mugwima}

A. Academic Professional Qualification

B. Architecture (JKUAT), MA. Planning: Urban and Regional Planning (UON), Cert.: CMHB (Lund University), Ph.D: Architecture (JKUAT)

B. Specialization

Urban and regional planning, Urban Design, Site Planning, Housing and Human Settlements Planning, Architectural Practice, Architectural audits, Conservation of natural and cultural Heritage, Urban resource management, Urban ecology, regeneration and conservation.

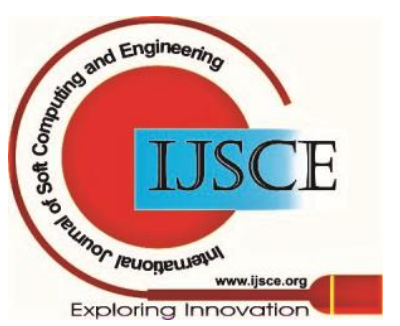

